\title{
ADAPTATIONS ASSESSMENT ON THE IMPACTS OF FLOODING UNDER CURRENT CONDITION AND CLIMATE CHANGE SCENARIO, CASE STUDY: CENTINI VILLAGE, INDONESIA
}

\author{
Adjie Pamungkas ${ }^{1}$, Sarah Bekessy² and Ruth Lane ${ }^{3}$
}

Diterima: 8 Agustus 2017

Disetujui: 29 Agustus 2017

\begin{abstract}
Reducing community vulnerability to flooding is increasingly important given predicted intensive flood events in many parts of the world. We built a community vulnerability model to explore the effectiveness of a range of proactive and reactive adaptations to reduce community vulnerability to flood. The model consists of floods, victims, housings, responses, savings, expenditure and income sub models. We explore the robustness of adaptations under current conditions and under a range of future climate change scenarios. We present results of this model for a case study of Centini Village in Lamongan Municipality, Indonesia, which is highly vulnerable to the impacts of annual small-scale and infrequent extreme floods. We compare 11 proactive adaptations using indicators of victims, damage/losses and recovery process to reflect the level of vulnerability. We find that reforestation and flood infrastructure redevelopment are the most effective proactive adaptations for minimising vulnerability to flood under current condition. Under climate change scenario, the floods are predicted to increase $17 \%$ on the average and $5 \%$ on the maximum measurements. The increasing floods result reforestation is the only effective adaptations in the future under climate change scenario.
\end{abstract}

Keywords: adaptations assessment, community vulnerability, climate change, and vulnerability model.

\section{INTRODUCTION}

Flooding in Indonesia is one of the main hazards since 1900s based on disaster data inventory from EM-DAT (2012). Most of the areas prone to flooding are located near the river and low-lying areas such in Centini Village, Lamongan Municipality. The village is one of the most affected villages in Bengawan Solo Catchment Areas. The village has been affected by two types floods (annual small-scale floods and infrequent extreme-scale floods). The annual flooding have changed the vilagers' pattern in farming. For example, the villagers start planting paddy after rainy seasons finishing off. For the extreme flood, the 2008 flood has inundated all the villagers' houses and evacuated all the villagers to the highest grounds in the village (Lamongan Municipal Disaster Unit, 2008). These two types of floods have made the villagers vulnerable to flood. Consequently, the village is classified as poor village by having 208 families under wealth standard households $(24 \%)$ and limited numbers (48 households or 4\%) of the wealth households' group (Lamongan Municipal Statistical Bureau, 2008). Furthermore, a large amount of non-permanent houses (269 houses) in the village

\footnotetext{
${ }^{1}$ Institut Teknologi Sepuluh Nopember - Surabaya

${ }^{2}$ RMIT University

${ }^{3}$ Monash University
} 
indicates a low level of economic capacity of the villagers (Laren Regency Profile, 2008). Therefore, this situation indicates that the village has high level of vulnerability to flooding from Bengawan Solo River.

In the long run, the level of vulnerability in the village will likely to be increase. Hidayat et al. (2008) suggest that the climate change will give significant increases on the rainfall along the Catchment of Bengawan Solo River. IPCC has also made prediction on the increases of rainfall due to climate change (cruz et al., 2007). In addition, Kaztney et al. (2010) have also predicted the increases of rainfall due to climate change in Australasia context. Therefore, under climate change scenario, the village may face more devastating floods in the future than in current situation.

To minimise the impact of floods in the village, the capacity of villagers in responding to flooding should be increased. Those responses can be generally called as adaptations (Biesbroek, Swart, \& Van Der Knaap, 2009; Smit \& Wandel, 2006). Current approaches are reactive and limited to individual responses based on the stakeholders' responses such as sounding the threat of floods and building temporary mezzanine (they call it as antru). Therefore, in this paper, we will propose proactive adaptations in minimising community vulnerability to flooding. In examining the proactive adaptations, we build a community vulnerability model through the system-dynamic analysis. Based on the model, we assess the adaptations under two conditions that are under current conditions and under climate change for future scenario. The assessment can select the most effective adaptations for both now and future scenarios. This selection is important to define the sustain-effective adaptation in order to minimise community vulnerability to flooding in the near future under climate change scenario.

\section{FLOODING IN CENTINI VILLAGE, INDONESIA}

Centini Village is one of 20 villages in Lamongan Municipality, Indonesia. Its location and topography (as shown in Figure 1) makes the village affected from annual and extreme floods. The annual floods have occurred for about less than half meters and inundated most of their rice fields, aquaculture and some of residential areas. Moreover, the extreme floods have inundated most of the village for about $1.5 \mathrm{~m}$. In this case, the villagers' livelihoods are totally disrupted by the flood such in the 2008 Lamongan Flood. The impact of 2008 Lamongan Flood in Centini Village includes 1,120 inundated house, 3,374 evacuated people, $123 \mathrm{Ha}$ inundated paddy fields.

\section{RESEARCH METHOD}

Community vulnerability model is built by using system dynamic analysis. The analysis can capture the special characteristics in the concepts of community and vulnerability. This model can then be used as a tool for assessing variety adaptations in order to minimise vulnerability level both in current and future scenarios. There are four main steps to assess the proactive adaptations through the model that are:

1. Finalising vulnerability factors, indicators, current adaptations and proactive adaptations.

2. Building the preliminary model structures and identifying the relationship formula among factors, indicators and adaptations.

3. Clarifying the relationship adaptations by the model to compare the effectiveness of adaptations based on its performance among factors, indicators and adaptations to the stakeholders.

4. Assessing the selected proactive on vulnerability indicators. The assessments are conducted in both scenarios (current conditions and climate change scenario). To 
reflect the vulnerability, the indicators of vulnerability are grouped into three victims, damage losses and recovery process. Pamungkas et al., (2014) formulate the indicator of vulnerability for modelling purposes and also urge the importance of modelling process in community vulnerability.

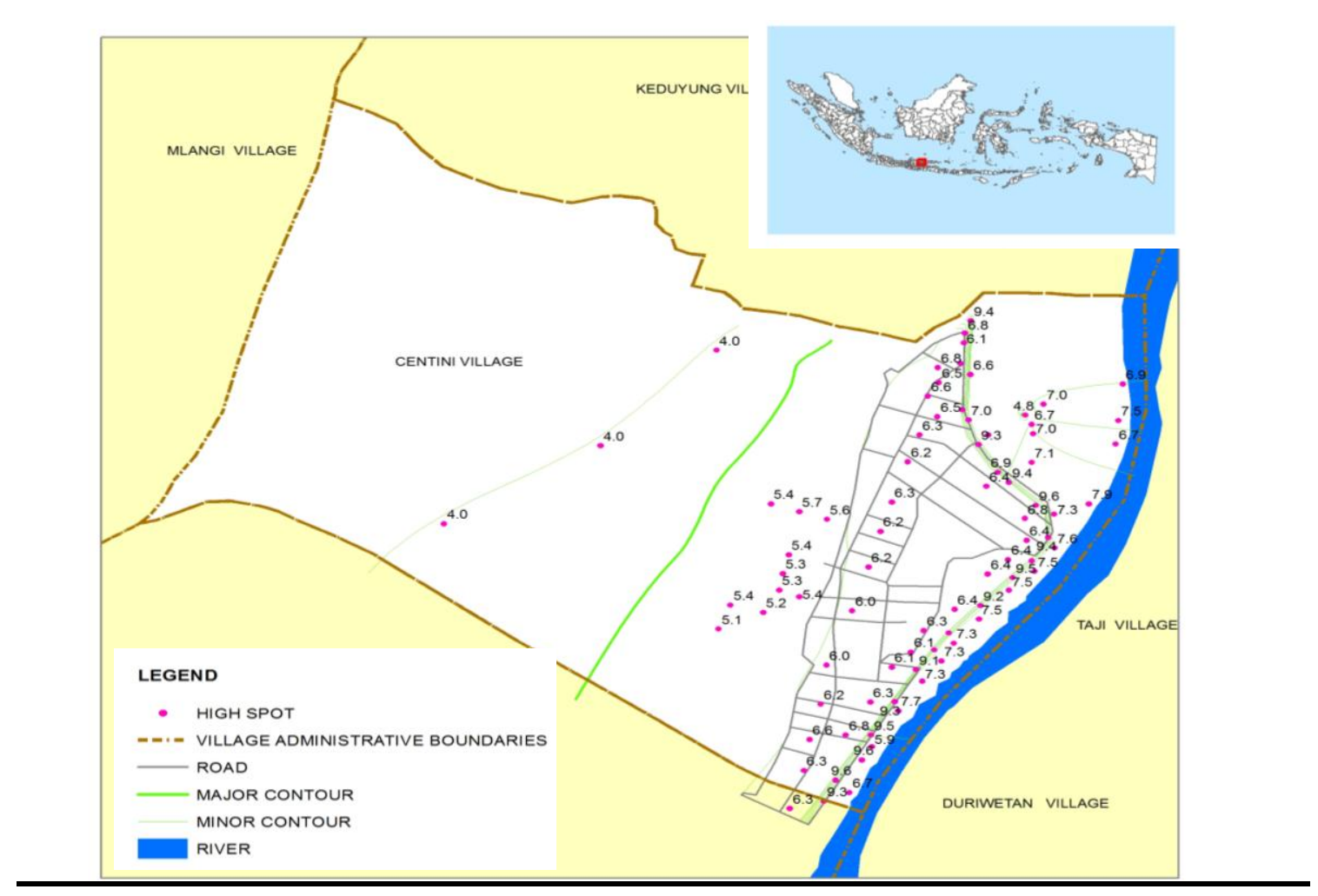

Figure 1 Centini Village Administrative Boundary

In the first step, we identify vulnerability factors and indicators from the literature. Pamungkas (2013) explains the selection process of vulnerability factors in detail.

Building the preliminary model is the second step of vulnerability assessment. The preliminary model classifies the factors and indicators into three types of variables in the model (stock, rate and information). The stock has a function of material accumulation in the model; rate has a function of regulating the flow of material from one stock to others; and the information has a function of influencing the rate (Sterman, 2000). The material in this context will be varied across the sub models. For the community vulnerability model, we established seven sub models that are; sub models of flood, victims, responses, housing, savings, income and spending.

To clarify the preliminary model, we conducted semi-structured interviews to 11 key informants. Those key informants are varies across the expertise related to the seven sub models. The clarification is important to verify information related to their daily life such as income, spending and responses to flooding. Clarification is also conducted by using relevant literature to validate the judgment. In this case, for example, I use run off coefficients to define the portion of water infiltration to the ground from rainfall (http://www.lmnoeng.com/Hydrology/rational.htm). Others are using government data such as from statistical bureau to validate the historical conditions such as population numbers, migration, crude death rate (CDR) and numbers of housings. Especially for the rainfall pattern in the future, I compare relevant six global climate change models (GCMs) 
for the Australasia context (Smith and Chandler, 2010; Katzfey et al., 2010). Those GCMs are GFDLC2.1, GFDLCM 2.0, ECHAM 5, HadCM, Micro 3.2 and Mk 3.5. To select one out of the six models, I simulate the model by changing rainfall data following the rainfall predictions from the six models under current condition. The simulations result six model outputs on inundation pattern. By comparing the six inundation patterns, I select GFDLCM2.0 model as the most relevant model to my case study than others. Therefore, the rainfall prediction will follow the predicted rainfall pattern on GFDLCM2.0 model under climate change scenario.

Table 1 Definition of Proactive Adaptations on the Model

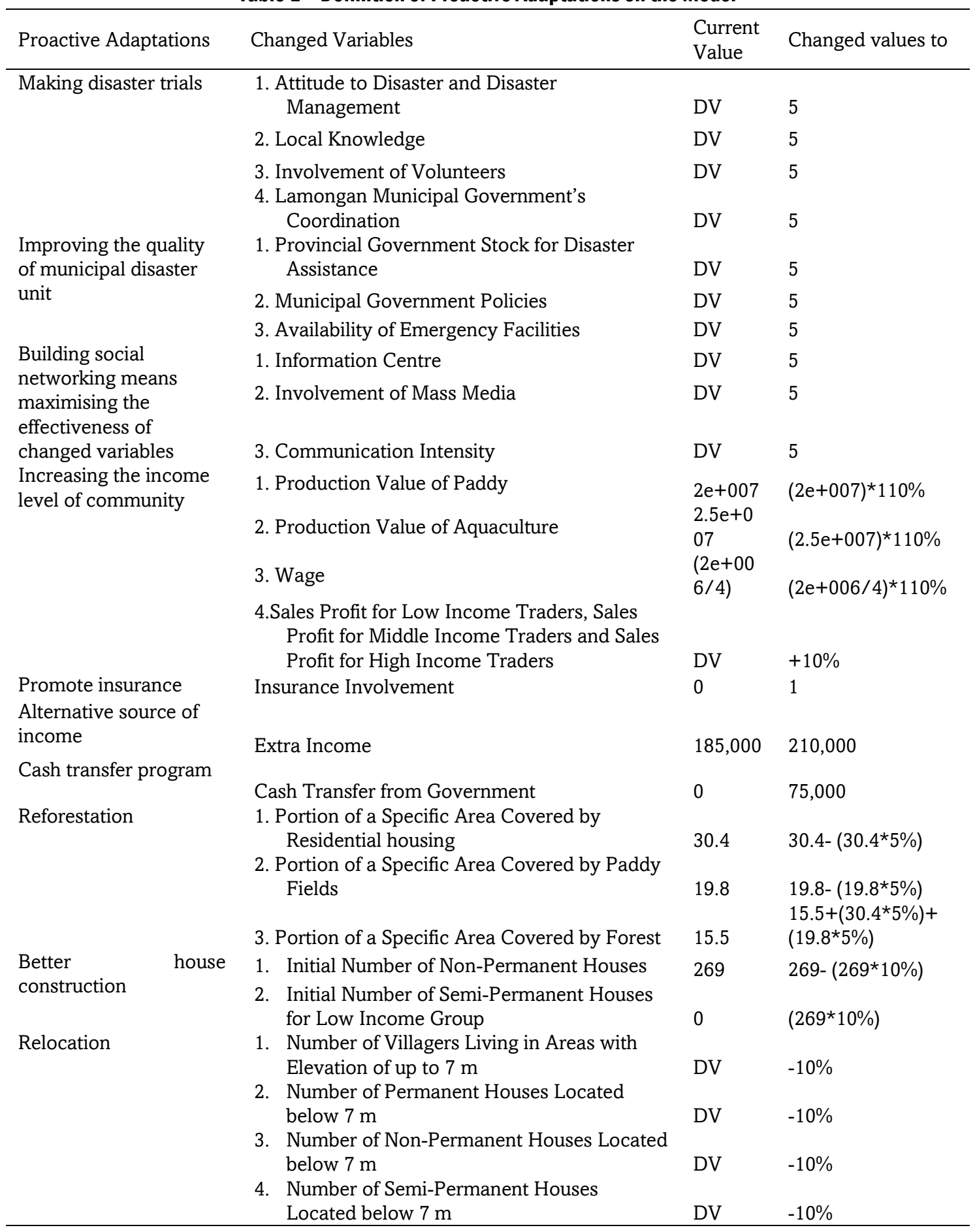




\begin{tabular}{llll}
\hline Proactive Adaptations & Changed Variables & $\begin{array}{l}\text { Current } \\
\text { Value }\end{array}$ & Changed values to \\
\hline $\begin{array}{l}\text { Flood infrastructure } \\
\text { redevelopment }\end{array}$ & $\begin{array}{l}\text { 1. Capacity of Drainage System } \\
\text { 2. Embankment Height }\end{array}$ & 007 & $(3.39 \mathrm{e}+007)^{\star} 105 \%$ \\
\hline Note: DV = Depends on the interactions between influential variables in current model
\end{tabular}

Note: DV $=$ Depends on the interactions between influential variables in current model

For the proactive adaptations assessment, we arrange some changes on the model based on the proposed proactive adaptations. Pamungkas (2013) suggests 11 proactive adaptations that are grouped into three categories (spatial plan, economic development and proactive community actions). The eleven adaptations will change the model differently as explained in Table 1.

Having those arrangements, we run the model for 1,000 iterations and 1,000 time steps (in weeks) for every assessment such as; first, running the model based on current condition or without any changes on the model. Second, running the model to assess proactive adaptations by changing related variables as on Table 1 . And then, we compare the three model outputs for every sub indicators to identify the most effective adaptation under current condition. Those assessments processes are repeated for the near future scenario under climate change only for the reforestation and flood infrastructure redevelopment as the most two effective adaptations. The main different is under climate change scenario, we use rainfall prediction data for 2040-2060 from GFDLCM2.0. Finally, we can compare the model outputs among under current condition and climate change scenario.

\section{RESEARCH OUTPUT}

Running the model under current condition results that the village is affected from annual floods and extreme floods. Figure 2 describes one out of 1,000 model outputs on the pattern of inundated height. The outputs also reflect the intensity of annual flood and probability of extreme flood in 1,000 weeks. The figure shows that the annual flood is a low and frequent flood in the village. Even though the flood is a low inundation, it inundates most of their farming areas (paddy field and aquaculture). Therefore, some of the villagers combine their farming system between paddy planting and aquaculture. Others have only rice field by waiting the rainy season to be end. The extreme flood is occurred in once or twice probabilities out of 1,000 weeks. Although it has small probabilities, the impact of the flood is quite devastated for example in 1967 and 2008 (stakeholders' information, 2012; EMDAT, 2012; Lamongan Municipal Disaster Board, 2008). This situation makes the villagers to have different farming style than other villages in Indonesia. For example, most of the paddy farming in Indonesia is started in the beginning of rainy season while the villagers start it in the end of rainy season.

Those inundation patterns above have varieties of severe impacts to the villagers. In terms of victims indicator, the highest probability of death in an extreme flood may occur for about 4 fatalities. In average, the total deaths in the village are about 26 persons in 1,000 weeks. In an extreme flood, all the villagers will be evacuated. In average, the evacuated villagers will be around 76 persons per week. In extreme situation, around half of the villagers $(2,844$ persons in a week) is affected by minor health problems such as skins, lungs and cold problems. The minor damaged houses ( 575 houses in a week) have around five times higher than major damaged houses. It is also around ten times higher than the number of collapsed houses in a week. The flooding has also made middle-income families as the most suffered families based on the economic losses criteria. The total value of economic losses for total middle-income families (231 households in the first week) is IDR 57,937,500 in a week. For the recovery indicator, a self-repair process on damage houses will take around 150s week out of 1,000 weeks. Two main difficulties in house repair are inundation height and money 
availability. When the inundation height is still more than $2.3 \mathrm{~m}$ from the lowest areas, the villagers will not start to repair the houses. With that inundation height, most of their houses are still inundated. Furthermore, the villagers cannot start repair if there is no money availability. Especially for the case of collapsed non-permanent houses, the government usually give financial assistance to rebuild the houses. Therefore, the repair of collapsed houses is shorter than other two types of damage houses (minor and major damage houses). The recovery process will also depend on the ability of villagers to recovery. Savings is one of the concepts to understand the villagers' financial ability for the recovery indicator. The simulations also result that the low-income families are the most incapable in the village to recover from flooding. The low-income families are also very vulnerable since there is a probability of having negative savings. In this context, the negative savings are the families' loan to support their daily life.

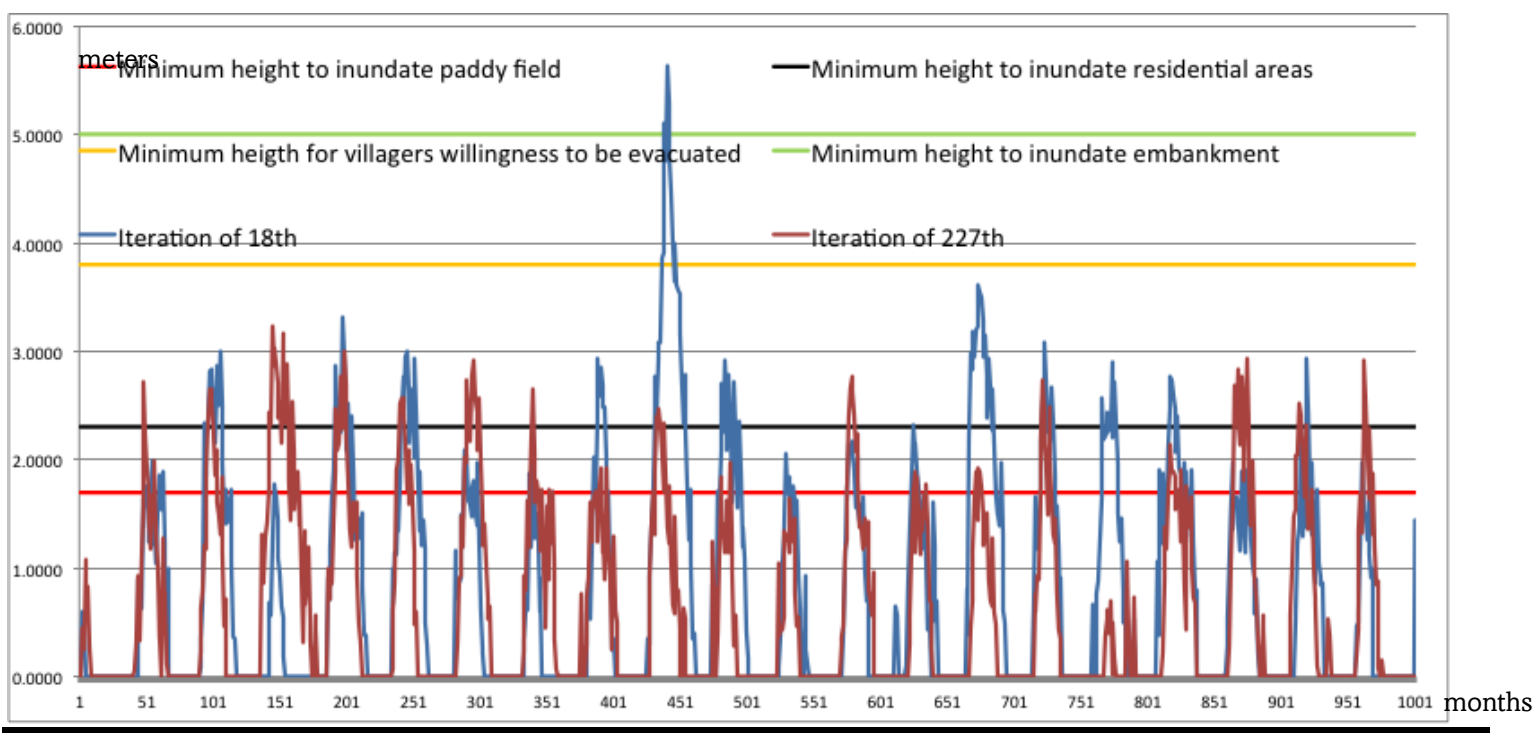

Figure 2 Predicted inundation heights from community vulnerability model outputs under current condition

To assess proactive adaptations, we change the model as explained in Table 1 for every proactive adaptation. The assessment will prioritise the effectiveness of all the eleven proactive adaptations under current conditions.

Based on the model outputs (Figure 3), reforestation and flood infrastructure redevelopment are the most two effective adaptations for all vulnerability indicators (victims, damage/losses and recovery). Both of adaptations can minimise all sub indicators in victims indicator significantly (around $-50 \%$ ). The adaptations can also minimise community vulnerability to the annual floods double compared to the vulnerability to extreme floods. For the damage/losses indicator, the effectiveness of both adaptations is similar to the victims indicator. For the recovery indicator, both of adaptation also significantly reduce the duration of impacts and increase the households' savings. The different between the two adaptations are reforestation has higher degree effectiveness than the flood infrastructure redevelopment. Other adaptations have fewer effectives than the two adaptations. Some adaptations only have significant effect to limited indicators such as; improving the quality of municipal disaster unit to only victims and damage/losses indicators and promoting better houses constructions to only damage/losses indicator. Figure 3 A-B-C shows the effectiveness of every proactive adaptation to every sub indicators in terms of percentage of changes. 
A: The effectiveness of proactive adaptations to vulnerability sub-indicator in Victims Indicator

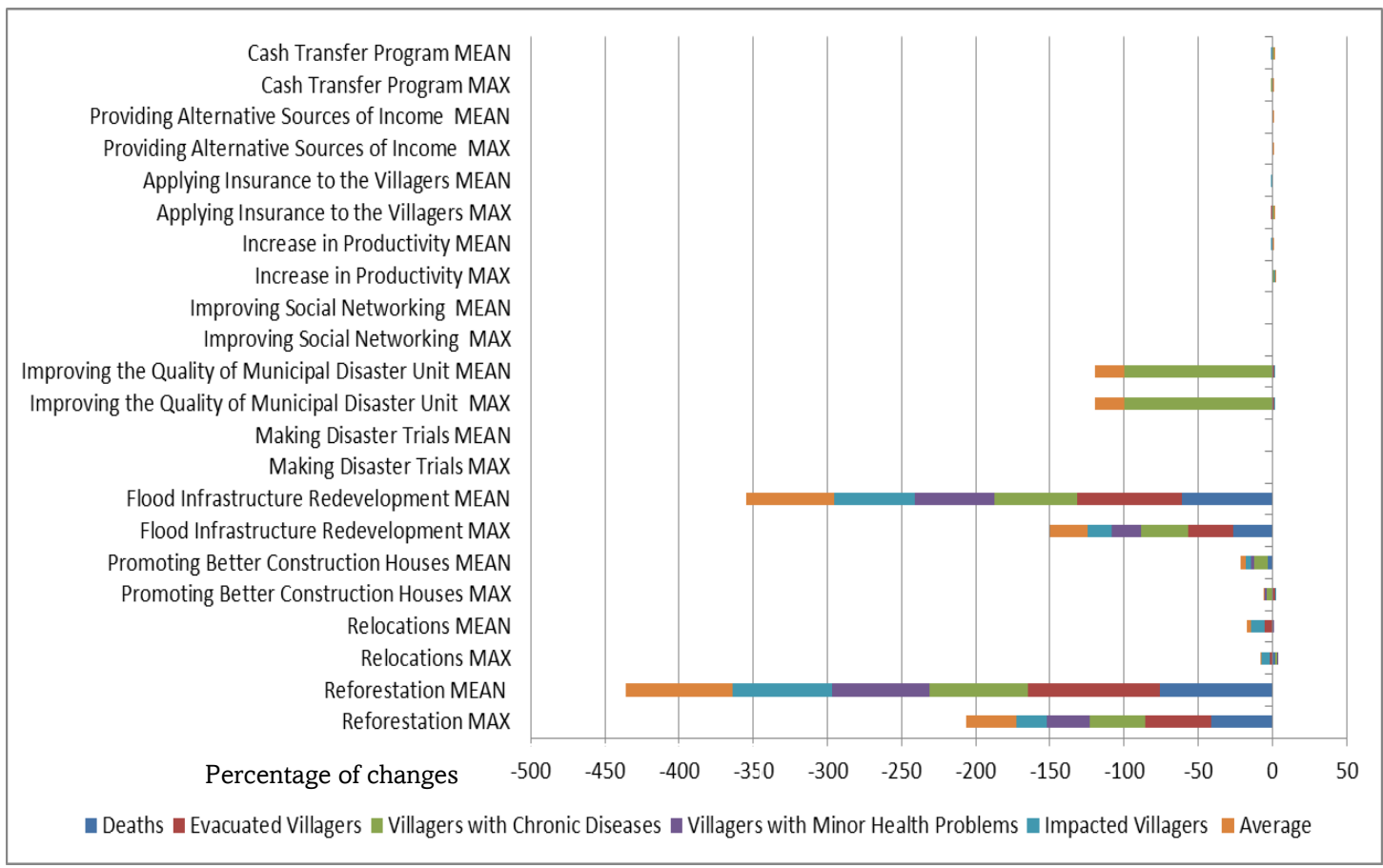

B: The effectiveness of proactive adaptations to vulnerability sub-indicator in Damage/Losses Indicator

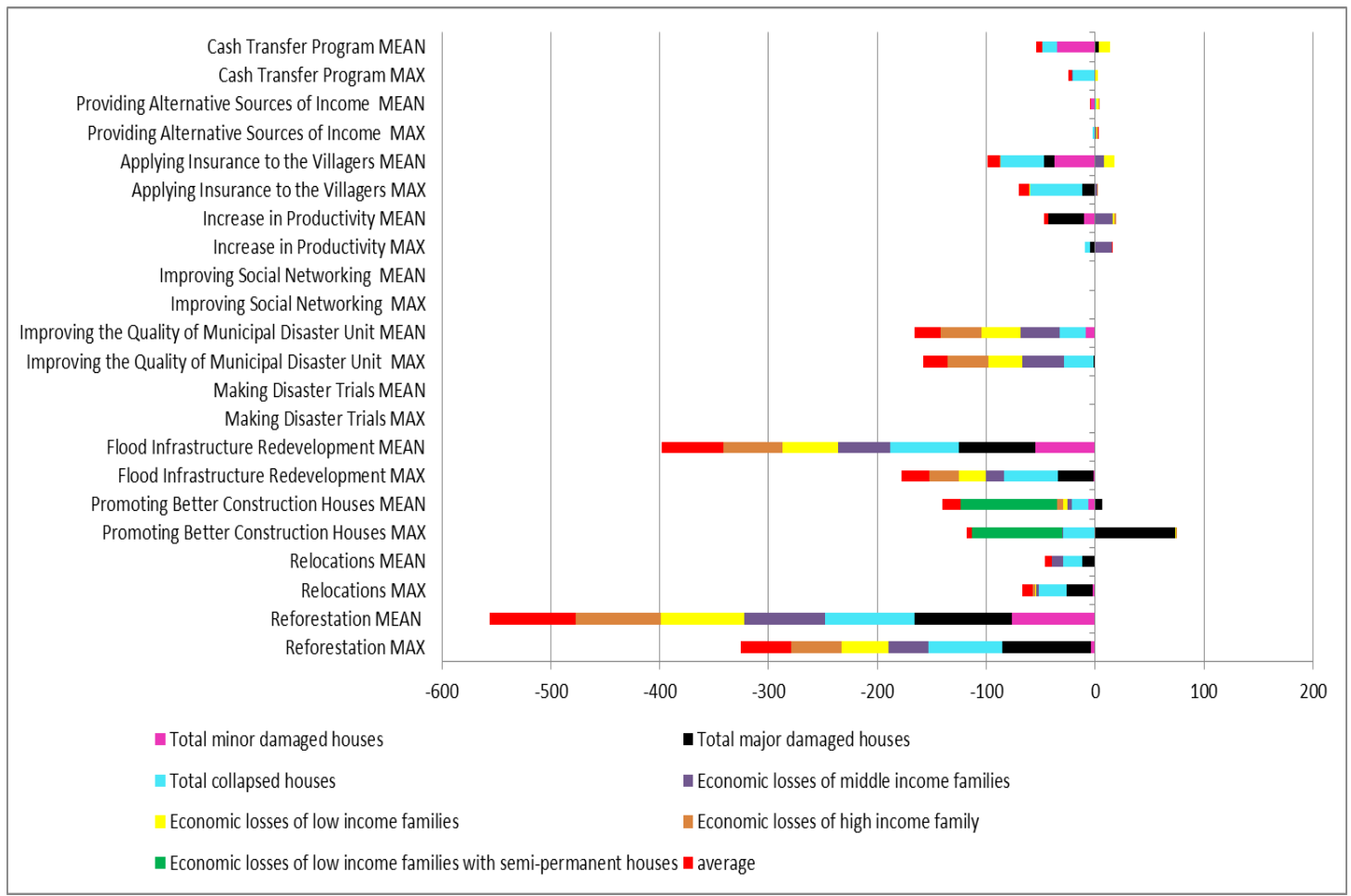

C: The effectiveness of proactive adaptations to vulnerability sub-indicator in Recovery Indicator 


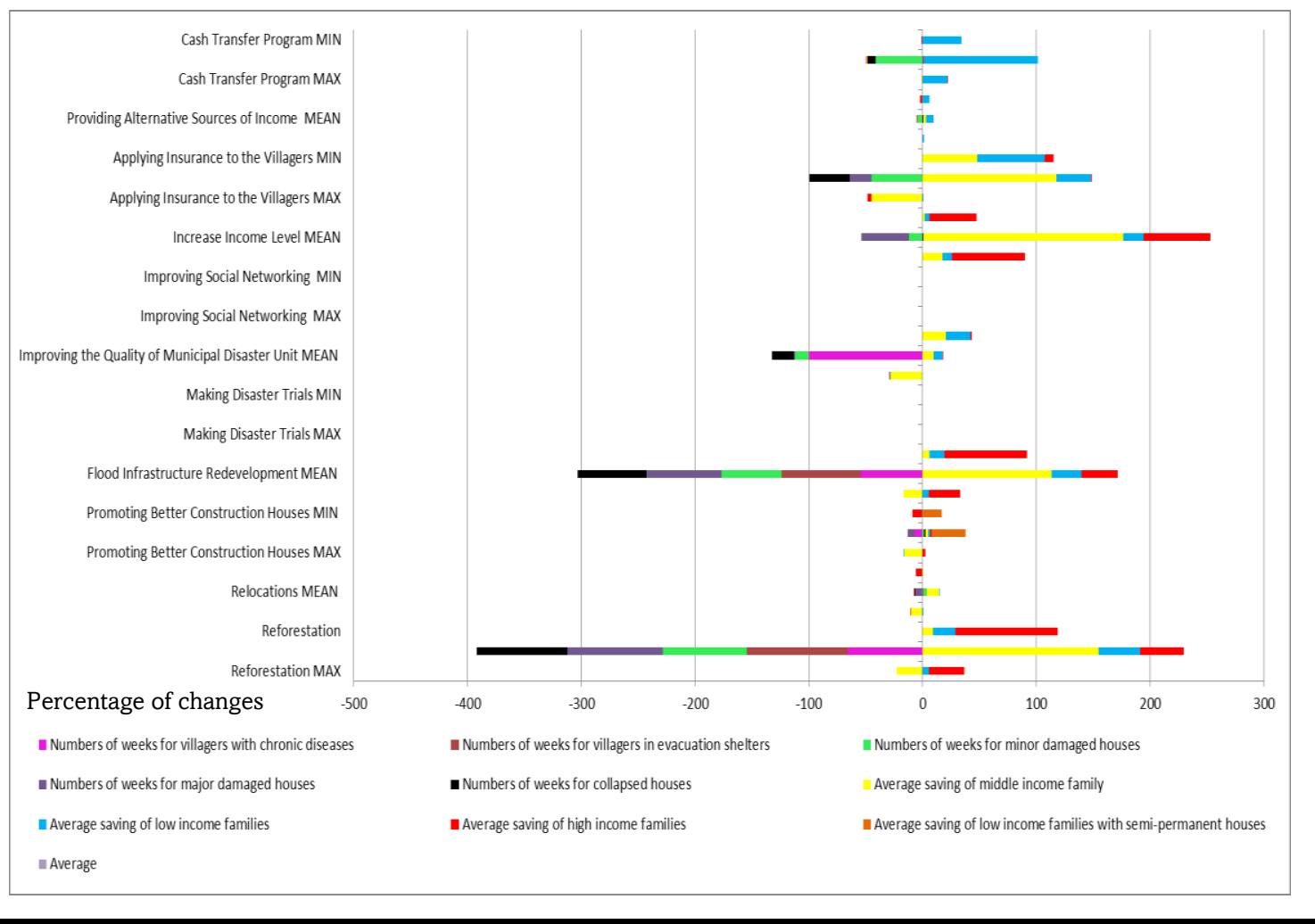

Figure 3 Model Outputs For Applying Proactive Adaptation On The Vulnerability Level Under Current Condition (A, B And C).

The next stage of modelling is assessing proactive adaptations under climate change scenario. The assessment is limited to only the two most effective adaptations under current condition, that are; reforestation and flood infrastructure redevelopment.

To get the model under climate change, we use predicted rainfall data from GFDLCM2.0 (as explained in Research Method Section). Afterward, we compare the model outputs based on rainfall data from GFDLCM2.0 among the time frame of current (19711999) and near future (2040-2060). From the comparison between current (1971-1999) and near future scenario (2040-2060), we can see that the flood will be increase in the case study. It increases for about $17 \%$ on the average measurement and around $5 \%$ on the maximum measurement. The increases mean that the annual flood in the near future under climate change scenario will more often and higher than in current time. In addition, the extreme flood will not much different in terms of its intensity. Unfortunately, the highest flood will be increase from $5.66 \mathrm{~m}$ to the $6.25 \mathrm{~m}$. Since the highest ground in the village (and usually the ground is used for evacuation shelters) can be reach by $5.5 \mathrm{~m}$ flood, the near future prediction of extreme floods can devastate the whole village. As a result, we can conclude that in the future, the flood will be more intense annual floods with a probability of having more devastated impacts on the extreme floods compared to the past experiences.

To assess the effectiveness of proactive adaptations under climate change scenario, we use the predicted rainfall data from GFDLCM2.0 for the near future scenario. Three types models to assess the adaptations are; the current model with current adaptations, near future model with current adaptations and near future with proactive adaptation. The effectiveness of proactive adaptations can be defined by comparing near future model with proactive adaptation verse current model with current adaptation (Comparison $\mathrm{A}$ ) and comparing near 
future model with proactive adaptations verse near future with current adaptations (Comparison B).

After simulating the three models for 1,000 iterations, we can conclude that reforestation remains an effective adaptation in minimising community vulnerability (Figure 4). It can minimise victims indicator both in Comparison A and B. It means that applying reforestation is much better than current adaptations both in now and near future time. This performance of reforestation adaptation also occurs for damage losses and recovery indicators. Even though the reforestation can effectively minimise community vulnerability in the future, the degree of reduces are lower compared to the current model in Figure 3. It means that the increases of flood due to climate change have lowered the degree of effectiveness of reforestations.

\section{A. Reforestation}

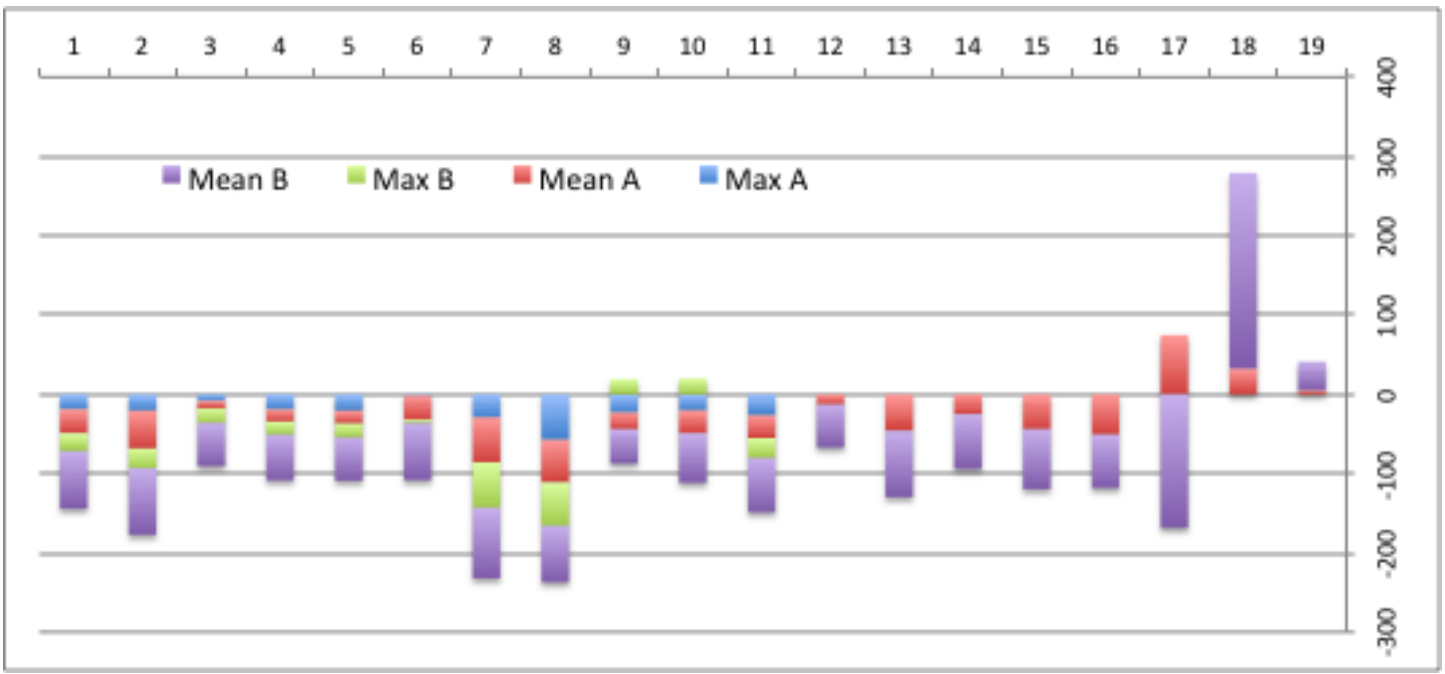

B. Flood Infrastructure Redevelopment

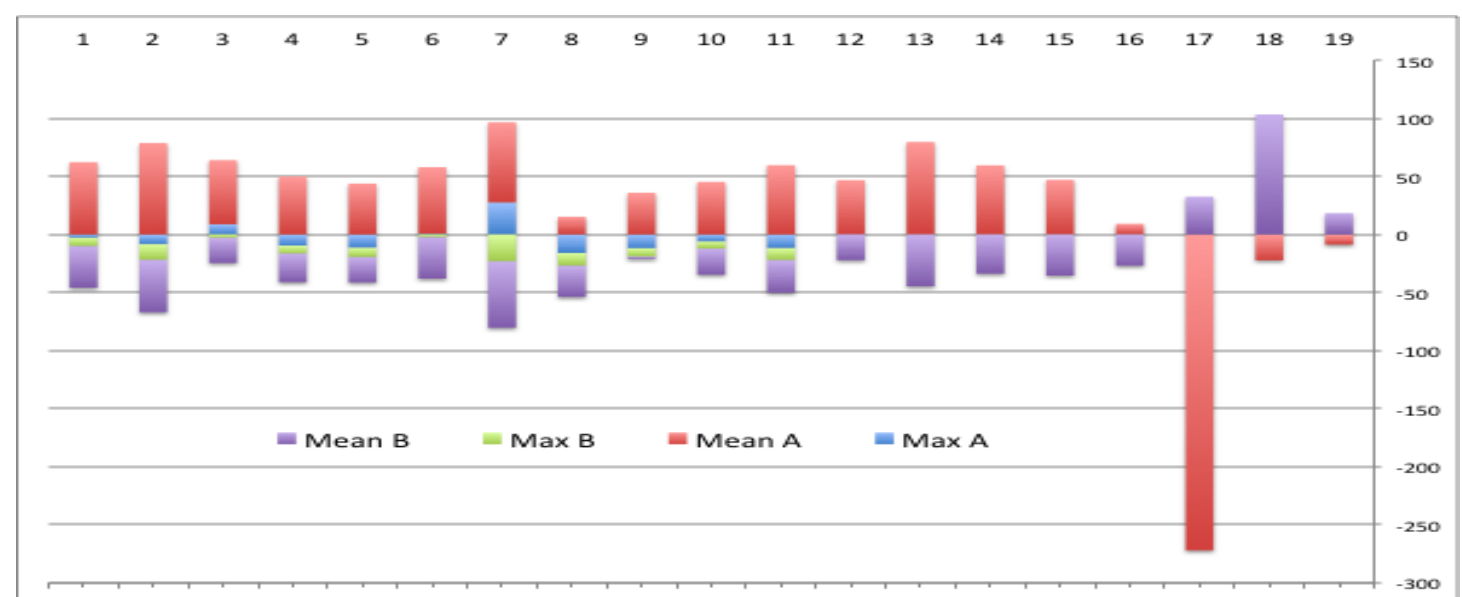

Figure 4 The Effectiveness Of Reforestation In Minimising The Sub Indicators In Community Vulnerability Level Under Climate Change Scenario

Note:

1 = Deaths

$=$ Evacuated villagers

$=$ Villagers with chronic diseases

$=$ Villagers with minor health problems

$=$ Impacted villagers 


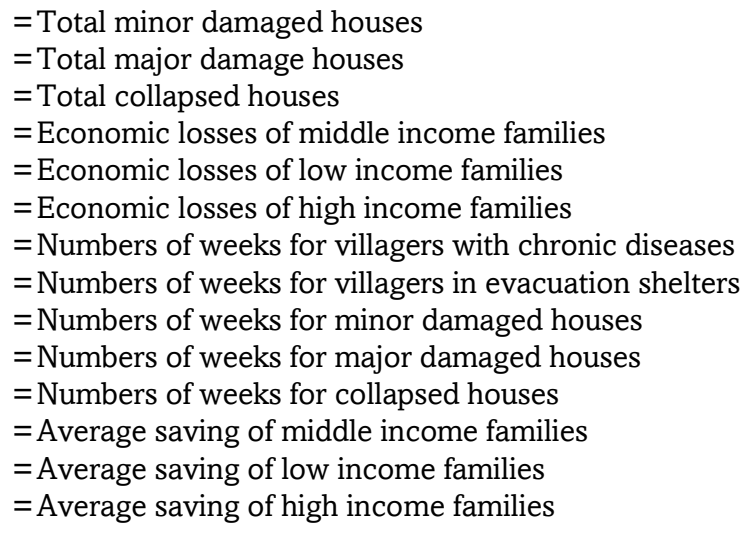

The assessment of flood infrastructure redevelopment in the near future scenario has resulted different pattern compared to the reforestation (Figure 4). The flood infrastructure redevelopment significantly minimise the indicators in Comparison B but it is insignificant in Comparison A. It is indicated by the mean B and max B are less than 0 and mean $A$ and $\max A$ are more than 0 for the indicator of victims and damage losses (Sub indicators of 111) and vice versa for the sub indicators of 12-19 (as recovery indicator) in the figure. This means that the adaptation is not effectively reduce victims indicator but it is still useful compared to continue applying current adaptations in the near future. As a result, we can conclude that the flood infrastructure redevelopment still has some benefits to reduce community vulnerability. Unfortunately, community still suffers from the increase flood's impacts as consequence of climate change scenario.

\section{DISCUSSION}

The model outputs in Section Research Output have illustrated that the villagers are suffered from the flood and will continue to experience increasing floods. The impacts of flooding are occurred in all vulnerability indicators (fatalities, damage losses and recovery). Those impacts are also increasing in the near future as the increases of flood. As a result, the villagers will be more vulnerable to flood in the near future as a consequence of climate change.

Applying proactive adaptations can significantly minimise the vulnerability level in the village under current condition. Reforestation effectively reduces vulnerability level by decreasing the amount of water discharged to the village. In addition, the flood infrastructure redevelopment significantly minimise community vulnerability level by increasing the flood infrastructure's capacity to accommodate water discharged in the village. Unlike the reforestation, the flood infrastructure redevelopment is not a sustain approach under climate change scenario. The increases of rainfall escalate the inundation pattern in the village. It result that the flood infrastructure redevelopment is insignificant in reducing vulnerability level in the near future. But, the adaptation is still better compared to have current adaptations in responding flood in the near future scenario.

In applying flood infrastructure redevelopment, a special concern should be placed particularly in the probabilities of collapsed infrastructures. The model shows that the probabilities of collapsed embankment in the near future is higher that in the current condition. The increased probabilities are caused by the increased inundation heights as a result of climate change. In the case of collapsed, the failure of infrastructures will cause severe impacts to the community. The collapsed infrastructure will discharge a large volume of water in a short time. Some cases of collapsed infrastructures are; dam break in Banqio 
(1975) made 230,000 fatalities, the six dam break due to earthquake and then rainfall in the southern parts of Quangxi Region, China (2008) (Lejon, Renofalt \& Nilsson, 2009). Another local case in Indonesia is the collapsed of Situ Gintung (a dam near Jakarta) killing around100 people and affecting 614 families (Jakarta Post, 2009).

From the research output, we understand that reforestation is an effective solution in minimising community vulnerability both for current and future times. Even though reforestation is a promising adaptation, the application of it faces several difficulties. One of them is lack of commitment from stakeholders in protecting their forest. Lamb (2011) suggests that the lack can be from the powerless authorised bodies to control the forest. Corbera, Estrada \& Brown (2010) highlight the lack of commitment as a result of poor coordination among relevant government agencies. Another hardship of applying reforestation is the development process near the forest. Some developments have expanded to the restricted areas including forest. Hartwick (2005) suggests that the increased development near forest results an intense land use competition. Tutu and Akol (2009) argue that the development process can cause land conversion from forest areas into other types of land uses such as agriculture, pastureland and settlement. This situation can be a cause of population increases (Tutu \& Akol, 2009) or poor policy making such as transmigration program in Indonesia (Palo \& Lehto, 2012).

\section{CONCLUSION}

Under system dynamic analysis, we built community vulnerability model. The model can evaluate various adaptations including reforestation and flood infrastructure redevelopment adaptations. Assessing eleven adaptations under current condition has resulted that only two adaptations are effective in minimising community vulnerability. Reforestation adaptation has minimised the indicators of victims around $-50 \%$, damage losses more than $-80 \%$ and recovery around $150 \%$ for increasing community savings and $70 \%$ for decreasing duration of recovery process. Moreover, the flood infrastructure redevelopment has slightly less effective than reforestation under current condition. The adaptation has minimised the indicators of victims for about more than $-50 \%$, damage losses for about $-50 \%$ and recovery more than $50 \%$ for increasing savings and more than $-50 \%$ for decreasing the duration of recovery. Therefore, we consider that both of the adaptations are vital for minimising community vulnerability under current condition.

The effectiveness of reforestation adaptation is consistent under future climate change scenario with less percentage. Reforestation is still able to minimise the vulnerability to flooding even though the flood is increase due to climate change. Consequently, the adaptation is also important for the community to minimise community vulnerability to flooding in the near future. Conversely, the effectiveness of flood infrastructure redevelopment has different pattern than reforestation under climate change scenario. The adaptation is ineffective in minimising future vulnerability level but it is still better than continuing with current adaptations. As a result, we consider that reforestation is an effective adaptation both under current condition and climate change scenario.

While reforestation is defined as effective approach, major challenges are still exist in implementing the adaptation. Lack of commitment and increasing development near forest areas are two out of the main causes of deforestation. Therefore, the stakeholders should highlight those challenges to avoid fallacies on the implementation stage of public policies in reforestation. 


\section{ACKNOWLEDGEMENT}

This article is part of my PhD thesis under the title of Vulnerability Assessment for Disasater Risk Management: A Case Study of Floods in Centini Village, Indonesia, conducted at RMIT University, Australia. The author expresses his gratitude to Directorate General of Higher Education of Indonesia and Centre of Excellence for Environmental Decisions (CEED) for funding the research, Prof. John Handmer and Dr. Joshua Whittaker from Centre for Risk and Community Safety -RMIT University.

\section{REFERENCES}

Biesbroek, G.R., Swart, R.J., \& Van Der Knaap, W.G.M., (2009) The mitigation-adaptation dichotomy and the role of spatial planning, Habitat International, 33, pp. 230-237.

Corbera, E., Estrada, M., \& Brown, K., (2010) Reducing Greenhouse Gas Emissions from Deforestation and Forest Degradation in Developing Countries: Revisiting the Assumptions, Climate Change, 100, pp. 355-388.

Cruz, R.V., Harasawa, H., Lal, M., Wu, S., Anokhin, Y., Punsalmaa, B. et al., (2007) Asia, in: Parry, M.L., Canziani, O.F., Palutikof, J.P., van der Linden, P.J., \& Hanson, C.E., (Eds.), Climate Change 2007: Impacts, Adaptation and Vulnerability, Contribution of Working Group II to the Fourth Assessment Report of the Intergovernmental Panel on Climate Change, Cambridge: Cambridge University Press, 469-506.

EM-DAT. (2012) Result for Country Profile: Indonesia, Centre for Research on the Epidemiology of Disasters CRED.

Fidrus. M., (2009) South Tangerang to Distribute Relief Funds For Burst Dam Victims, October 20, available at http://www.thejakartapost.com/news/2009/10/20/south-tangerang-distribute-relief-funds-burst-damvictims.html (accessed 25 May 2012).

Hartwick, J.M., (2005) Deforestation and Population Increase, in: Kant and Berry (Eds). Institutions, Sustainability, and Natural Resources, Institutions for Sustainable Forest Management, 155-191.

Hidayat, F., Sungguh, H.M., \& Harianto (2008) Impact of Climate Change on Floods in Bengawan Solo and Brantas River Basins, Indonesia, Paper presented at River Symposium.

Katzfey, J., McGregor, J., Nguyen, K., \& Thatcher, M., (2010) Regional Climate Change Projection Development and Interpretation for Indonesia, The Centre for Australian Weather and Climate Research: a Partnership between CSIRO and the Bureau of Meteorology.

Lamb, D., (2011) Regreening the Bare Hills, World Forests, 8, 1-39. DOI 10.1007/978-90-481-9870-2_1.

Lejon, A.G.C., Renofalt, B.M., \& Nilsson, C., (2009) Conflicts Associated with Dam Removal in Sweden, Ecology and Society, 14 (2): 4.

Pamungkas, A., Bekessy, S.A., \& Lane, R., (2014) Vulnerability Modelling to Improve Assessment Process on Community Vulnerability, Procedia - Social and Behavioral Sciences, 135, 159 - 166.

Pamungkas A., (2013) Factors for enhancing community resilience to flood in Centini Village, Indonesia, Paper presented at PRSCO 2013 (the 23rd Pacific Conference of the Regional Science Association International (RSAI) and The 4th Indonesian Regional Science Association (IRSA) Institute, Bandung-Indonesia.

Palo, M., \& Lehto, E., (2012) Deforestation in the Tropics in World Forests: Private or Socialistic Forestry? Business Media B.V. 4-130. DOI 10.1007/978-90-481-3896-8_5.

Smith, I., \& Chandler, E., (2010) Refining Rainfall Projections for the Murray Darling Basin of South-east Australia - the Effect of Sampling Model Results based on Performance, Climate Change, 102, 377-393. DOI 10.1007/s10584-009-9757-1

Sterman, J.D., (2000) Business Dynamic: System Thinking and Modelling for a Complex World. Boston: Irwin McGraw-Hill.

2008, 'Inventarisasi Data Kerusakan dan Kerugian Pasca Bencana Banjir dan Tanah Longsor Provinsi Jawa Tengah dan Propinsi Jawa Timur: Kabupaten Lamongan', Lamongan Municipal Disaster Unit. 